\title{
Professor Emérito Richard Emil Bucher (1940-1997)
}

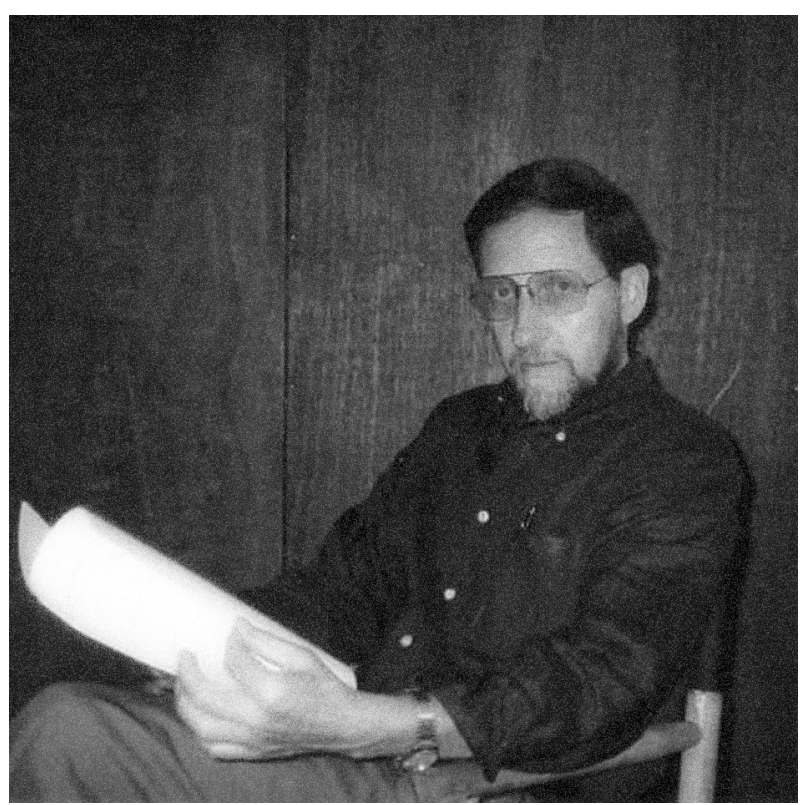

Figura 1. Professor Richard Emil Bucher, in memorian.

Fonte: Acervo familiar.

\section{Memorial sobre o Professor Richard Emil Bucher ${ }^{1}$}

\section{Caminhos antes do Brasil (Suíça, Israel, Bélgica) ${ }^{2}$}

Richard Emil Bucher nasceu em 29 de marco de 1940, em Zurique, Suíça, filho de Paul Bucher e Agnes Lattner Bucher. Nesta cidade passou sua infância, adolescência, fez estudos em agronomia e, ao terminar, rasgou seu certificado, pois concluiu que este não teria utilidade para si. Partiu então para começar estudos de hebreu, inicialmente, e, em seguida, estudos bíblicos na Universidade de Jerusalém/Israel, onde passou alguns anos na Maison St. Isaie. A seguir, foi para Fribourg na Suíça onde se recolheu num retiro em um convento durante 40 dias com objetivo de pensar, meditar, sobre seu futuro, o que resultou na decisão de iniciar seus estudos em Filosofia e Psicologia em Louvain, na Bélgica. Lá obteve os títulos de graduação em Filosofia

1 Texto produzido pelo Prof. Ileno Izídio da Costa do Departamento de Psicologia Clínica da UnB como parte do processo de outorga de título de Professor Emérito ao Professor Richard Bucher. A editora agradece pela cessão deste texto para publicação.

2 Este texto é uma combinação de informações e de redação feitas ou obtidas junto a familiares do professor (Suíça), sua ex-esposa (Profa. Júlia Bucher), por prospecção de diversos materiais (entrevistas, curriculum vitae, publicações etc), seu memorial (quando de sua avaliação para a categoria de Professor Titular, em 1989) e a vivência do professor relator, na condição de ex-aluno, ex-estagiário, membro do Centro de Estudos Freudianos, membro inicialmente participante do Cordato e participante de seminários, palestras e estudos diretamente com o professor homenageado, de 1980 até o seu falecimento.
(1967), em Psicologia (1968), mestrado em Filosofia (1968) e em Psicologia (1969).

Em 1969 foi convidado pelo Professor Jacques Schotte para ser assistente (TP-20) no Centre de Psychologie Différentielle et Clinique da Faculdade de Psicologia e das Ciências da Educação na Universidade de Louvain. Trabalhou durante seis anos nesta função, ministrando as partes práticas de matérias psicodiagnósticas (testes de Rorschach e Szondi) e preparando sua tese de doutoramento, concluída em 1974 e defendida em março de 1975. Dentro deste período, de 1970 a 1972, exerceu a função de psicólogo clínico no Service de Psychopatologie das Clínicas Universitárias de Louvain, realizando atividades psicodiagnósticas e psicoterapêuticas. Também nesse período, participou dos seminários sobre a América Latina, começou a estudar língua e cultura portuguesa - e posteriormente brasileira - e iniciou sua formação em psicanálise na École Belge de Psychanalyse, da qual se manteve como membro exterior. Teve como mestres Jacques Schotte ${ }^{3}$,

3 Psiquiatra, psicólogo e psicanalista, formado em medicina e filosofia, professor, desde 1964, na Université Catholique de Louvain e na Katholieke Universiteit te Leuven, ensina uma psicologia clínica enquanto ciência e prática humana. Pensador de renome internacional, orador legendário em muitas línguas, é reconhecido na Europa e nas Américas, em especial por permitir pensar o que podemos chamar de uma "antropopsiquiatria" Seus mestres foram Szondi, Binswanger, Lacan, Tosqueles, Maldiney e Kuhn. 
Antoine Vergote ${ }^{4}$ e Leopold Szondi ${ }^{5}$ que, naquela ocasião, ministrava aulas em Louvain.

Em Paris seguiu Seminários de Psicanálise dentre os quais os de Jacques Lacan ${ }^{6}$. Este período foi muito produtivo, pois ao se preparar intelectualmente, já produzia trabalhos científicos publicados na Fuillets Psychiatriques de Liege e Revue Belge de Psychanalise. Sua tese de doutorado, intitulada "Depressão e Melancolia", que fez interface com a clínica psicanalítica, o psicodiagnóstico (Teste de Szondi) e a história da nosografia psiquiátrica, foi publicada em alemão e em português. O interesse pela Psicopatologia expresso em sua tese de doutorado o acompanhou por toda a sua vida, embora se dirigindo, em termos de pesquisa e de abordagem institucional, a um tema cada vez mais específico, a saber, as toxicomanias ou, de maneira mais ampla, como ver-se-á a seguir, aos problemas das drogas na sociedade ${ }^{7}$ e posteriormente aos problemas de meninos de rua.

\section{Desenvolvimento da trajetória acadêmica, clínica e institucional}

Tendo terminado seus estudos na Universidade de Louvain recebeu convites para trabalhar em Zurique, no Centro dirigido pelo Prof. Leopold Szondi ou para continuar trabalhando na Bélgica. Optou, no entanto, após diversos contatos com universidades brasileiras, por aceitar o convite do Departamento de Psicologia da Universidade de Brasília, feito na ocasião por meio do Prof. Luiz Pasquali, para o cargo de Professor Adjunto I em 01/01/1976. Ao chegar em Brasília, Richard Bucher juntamente com os professores Júlia Bucher e Carlos Vieira iniciaram um grupo de trabalho para desenvolver um projeto de uma clínica de Psicologia que atendesse às necessidades de estágio e de pesquisa nas áreas de saúde mental e de orientação escolar, juntando-se, posteriormente, o Prof. Jorge Ponciano.

A partir desse projeto foi criado a Unidade Especial de Ensino e Pesquisa (UEEP) do Departamento de Psicologia. A UEEP foi coordenada pelo Prof. Richard Bucher que estruturou toda a parte de atendimentos, supervisão de estágios, de ensino e pesquisa dentro desta unidade. Desenvolveu critérios éticos para o atendimento conforme documentação da época. Nesse período também desenvolveu, juntamente com a Profa. Júlia Bucher e mais tarde com a Prof. Annik Rosiers Fonseca, um trabalho clínico e de pesquisa voltado para a oncologia em colaboração com hospitais e médicos especialistas na

4 Ex-padre, psicanalista e teólogo, professor emérito da Katholieke Universiteit te Leuven, Bélgica, publicou importantes obras sobre as interfaces entre a psicanálise e a religião.

5 Lipót Sonnenschein nasceu na Eslováquia, estudou medicina, especializando-se em Psiquiatria. Tornou-se um ávido leitor das obras de Freud. Fez psicanálise com Adolf Neumann, discípulo de Sandor Ferenczi, colaborador direto de Freud. É o grande autor da "Psicologia do Destino". Fugindo da guerra, foi acolhido na Suíça. Sua teoria teve penetração em toda a Europa, no Brasil, no Japão e em alguns outros países em outras partes do mundo.

6 Desnecessário apresentar a contribuição de Jacques Lacan para a cultura ocidental.

7 Conforme suas próprias palavras em seu memorial de defesa para o cargo de Professor Titular do Instituto de Psicologia, em março de 1989. área da cidade. Introduziu o conhecimento da psicanálise através do ensino e da prática supervisionada. Colaborou na organização do curso de Mestrado em Psicologia, bem como na reestruturação do curso de graduação introduzindo disciplinas nas áreas da Psicanálise, da Psicopatologia e das Teorias e Técnicas Psicoterapêuticas.

Formou inúmeros alunos que hoje são professores em várias universidades brasileiras, muitos psicanalistas que hoje atuam na área e muitos outros psicólogos clínicos atuando em vários campos da saúde. Na área da extensão universitária ministrou o primeiro curso de extensão universitária a respeito da teoria de Lacan e o retorno a Freud na Universidade de Brasília. Também junto com a professora Júlia Bucher ministrou o curso sobre "Sexualidade Humana: implicações psicodinâmicas" para médicos e profissionais de saúde no Hospital Presidente Médici na época. Dentre as inúmeras atividades de extensão organizadas pelo Prof Richard, destacou-se a organização do Seminário "Freud no mundo contemporâneo" por ocasião do aniversário da morte de Freud.

\section{Memorial Cronológico Sucinto}

\section{Breve histórico da formação e do exercício profissional}

1946 a 1967 - Escolas primária e secundária em Zurique, Suíça.

1955 a 1957 - Aprendizado agrícola.

1957 a 1959 - Escola técnica de agricultura (Zurique).

1959 a 1962 - "Ferngymnasium" em Zurique, concluído com diploma federal de "Maturidade" (Humanidades greco-latinas).

1964 a 1967 - Graduação no curso de Filosofia na Université Catholique de Louvain (UCL), Bélgica.

1965 a 1968 - Graduação no curso de Psicologia, UCL, Bélgica.

1967 a 1968 - Mestrado em Filosofia, UCL.

1968 a 1969 - Mestrado em Psicologia, UCL.

1969 a 1975 - Doutoramento em Psicologia.

1965 a 1975 - Formação psicanalítica teórica e prática na École Belge de Psychanalyse, se tornando membro efetivo e, após estar no Brasil, membro efetivo no exterior.

1969 a 1975 - Assistente meio expediente na Université Catholique de Louvain, Faculté de Psychologie, Centre de Psychologie Différentielle et Clinique, sob a direção do Prof. Dr. Jacues Schotte.

1976 - Professor visitante a nível de Adjunto 1 - DE na Universidade de Brasília, Departamento de Psicologia.

1976 a 1979 e 1981 a 1984 - Coordenador da UEEP do

Departamento de Psicologia da UnB

1978 a 1992 - Fundação do Centro de Estudos Freudianos

1979 - Admitido em 01/09 no quadro permanente de professores da UnB.

1981 - Mudança do regime de trabalho para TP-20 em 01/07.

1984 a 1985 - Estágios Centre Medical Marmottan em Paris, especializado no atendimento a toxicômanos, sob a direção do Prof. Dr. Claude Olivenstein.

1985 - Nomeado executor dos convênios para implantação do "Projeto CORDATO". 
1986 - Abertura oficial do CORDATO, vinculado ao Instituto de Psicologia da UnB, com inauguração oficial em 11/04/1986. Nomeado Coordenador do Cordato até 1991.

1989 - Nomeado assessor do Ministério da Saúde para o "Projeto Previna", visando à prevenção de DST/AIDS entre usuários de drogas.

1990 - Aprovado por concurso público e nomeado para o grau de Professor Titular.

1990 - Participação na elaboração do "Programa Valorização da Vida" da ABEAD (Associação Brasileira de Estudos de Álcool e Outras Drogas), encomendado pelo Ministério da Educação.

1991 a 1992 - Consultor da USAID para assuntos de drogas.

1993 - Assessor da Representação da UNESCO no Brasil em educação preventiva para qualidade de vida, drogas e AIDS.

1996 - Proposta de criação do "Consultório de rua", voltado para a educação para a saúde na rua de crianças e adolescentes.

\section{Seu percurso e produção na $U n B$}

Assim, desde 1976, o Professor Richard Bucher lecionou regularmente matérias na graduação e no mestrado ${ }^{8}$, orientou trabalhos finais de mestrado, participou de bancas, supervisionou alunos em estágio clínico, participou de atividades administrativas, realizou pesquisas e publicações, engajou-se em atividades de extensão, sem contar com atividades profissionais didáticas desenvolvidas fora da Universidade.

Em 1981, o professor Bucher pediu mudança do regime de trabalho para tempo parcial com a justificativa de precisar do exercício da Psicanálise para alimentar a sua pesquisa clínica, que, em suas próprias palavras, era "impossível na universidade com dedicação exclusiva", pelo menos com a seriedade e o compromisso científico, profissional e social que sempre teve. Isto resultou $\mathrm{em}^{9}$ :

- 16 publicações (artigos completos) internacionais em francês, alemão, inglês e espanhol ${ }^{10}$;

- 69 publicações (artigos completos) nacionais, sobre diferentes temas: psicanálise, ideologia, drogas, psicofarmacologia, confitos conjugais, lei, depressão, melancolia, técnicas projetivas, classificação nosográfica, sexualidade,

8 Na Graduação: Tópicos Especiais em Psicodiagnóstico, Psicologia Preventiva e Higiene Mental, Teorias Psicanalíticas, Psicopatologia, Teorias e Técnicas Psicoterápicas, Técnicas Projetivas, Tópicos Especiais em Psicoterapia, Estágios Supervisionados Psicólogo: Na Pós-Graduação: Tópicos Especiais e Psicologia Clínica, Psicanálise e Fenomenologia, Psicoterapia, Psicodinâmica da Personalidade, Processos de Mudança da Personalidade, Epistemologia da Psicologia, Processos Inconscientes.

9 Os dados aqui constantes são fruto de pesquisa em currículos datilografados pelo próprio professor e no material coletado pelo seu filho Jacques Philippe, a quem este professor relator agradece pela presteza e disponibilidade em contribuir com este documento, além de elogiar, de público, a sua permanente dedicação à memória de seu pai ao coletar todo o material possível, organizar suas publicações, entrevistas, livros, entrevistas, rascunhos etc. Neste sentido, além dos documentos oficiais, vão junto a este memorial todos os documentos possíveis de comprovar a inequívoca produção e dedicação do professor Bucher à UnB, à Brasília e ao Brasil.

10 O Prof. Richard Bucher dominava, além de sua língua materna (Alemão), Francês, Inglês, Espanhol, Holandês e o Português. alcoolismo, delinqüência juvenil, casal, esquizofrenia, linguagem, loucura, diabetes, Freud, tentativas de suicídio, psicooncologia, índios, marginalização, fenomenologia, toxicomanias, câncer de mama, transgressão, direitos humanos, ética, prevenção, mito, destino e formação do psicanalista e do clínico;

- oito livros em português e três em alemão, dentre os quais se tornaram clássicos: "Depressão e Melancolia", "A psicoterapia pela fala", "As drogas e a vida", "Drogas e drogadicação no Brasil" e "Drogas e Sociedade nos tempos de AIDS". Vale ressaltar que tais livros hoje são referências nacionais e até internacionais como textos básicos sobre psicoterapia, epidemiologia da droga no Brasil e o tratamento da drogadicção, chegando inclusive a ser vendido no mundo inteiro por meio de instituições comerciais extremamente populares, tais como as Lojas Americanas, no Brasil;

- nove orientações de mestrado concluídas ${ }^{11}$.

Por outro lado, após ter sido coordenador, durante três anos e meio (1976 a 1979), da UEEP (Unidade Especial de Ensino e Pesquisa) do Departamento de Psicologia da UnB, voltou a ser coordenador por mais três anos (1981 a 1984), apesar do contrato parcial, funcionando a clínica, sob sua coordenação, com um elevado número de atendimentos realizados por estagiários, professores e alunos de extensão. Durante quatro anos realizou, no Departamento de Psicologia Clínica, grupos terapêuticos gratuitos para alunos e pacientes da comunidade em geral, bem como, durante uns 10 anos, realizou atendimentos gratuitos, sem descuidar ou desmerecer a carga horária e a qualidade costumeiras de docência.

Em 1984/1985, sob o patrocínio do CNPq e de instituições européias, o professor Richard realizou um estágio de três meses no Hospital Marmottan em Paris, especializado no atendimento a toxicômanos, sob a direção do Dr. Claude Olivenstein. O professor refere em seu memorial que "desde seus estudos na Bélgica que se interessava pelos problemas decorrentes do abuso de drogas, primeiro quanto à personalidade do toxicômano, depois quanto à clínica e ao tratamento". Deste estágio e interesses surgiu sua primeira grande contribuição psicossocial à comunidade brasiliense, em primeiro lugar, e ao Brasil, em seguida, que foi a proposição e a implementação de um centro sobre drogas vinculado à UnB que denominou como Centro de Orientação sobre Drogas e Atendimento a Toxicômanos (CORDATO), implantado no início de 1986 graças a um convênio com o Ministério da Justiça. Apesar das dificuldades, conseguiu fazer um convênio com o GDF (Secretaria de Saúde) em 1987 e, em 1988, um convênio com o INAMPS para a devida manutenção de seu primeiro grande projeto comunitário. Neste centro, sob sua coordenação, montou uma equipe verdadeiramente multidisciplinar composta de 15 profissionais, exercendo atividades de prevenção, atendimento terapêutico e pesquisa na área de drogas. A repercussão na comunidade brasiliense foi enorme, abrindo e ampliando diferentes frentes de lutas no tema. Incansável batalhador pela qualidade de sua atuação, seja como professor, como clínico ou consultor, o Professor Bucher conseguiu, com o

11 Número constante da última versão de seu Currículo Lattes no CNPq (Agosto de 1999), confirmada na página da pós-graduação do Instituto de Psicologia no item "Sumários de Dissertações de Mestrado e Teses de Doutorado". 
Cordato, apoios e patrocínios nacionais e internacionais. Tudo isto com base na sua consistente e complexa proposta de articulação dos conhecimentos da Fenomenologia, da Psicanálise, da Antropologia e sobre as drogas.

\section{De uma conclusão e de um reconhecimento}

Pelo todo exposto, inegável admirar, reconhecer e reverenciar a contribuição do Prof. Richard Emil Bucher à Psicanálise, à UnB, à Brasília e ao Brasil. Infelizmente, o Professor Richard faleceu, precocemente, aos 57 anos, em 17 de julho de 1997, em plena atividade profissional, intelectual e social.

Creio estar evidenciada sua profunda e profícua contribuição na formação de profissionais da área de saúde e de ciências humanas, em geral, nas questões que envolveram uma reflexão conseqüente sobre a Psicanálise, a Clínica, a Filosofia, a Antropologia e, em particular, sobre o inevitável engajamento no cuidar do sofrimento psíquico humano, expresso em particular na drogradicção. Em seus últimos anos de vida, estava começando a se engajar em projetos sociais mais amplos, a assim chamada "clínica na rua", "através do projeto de intervenção nas condições de vida na rua de crianças e adolescentes, através de ações planejadas de uma presença educativa, de escuta, compreensão e orientação"12.

O professor Bucher, em seus últimos anos de atuação, influenciou, pelas suas publicações, reflexões, posturas e atuação político-social, toda a concepção governamental da não-criminalização das drogas no Brasil, em especial a maconha. Richard Bucher defendia a idéia de que não existe droga a priori, considerando que, no estudo da evolução da toxicomania, mais do que o efeito puramente fisiológico da droga, o que importa é compreender a interpretação que o indivíduo dá à sua experiência, ao seu estado e à motivação que o impele a um consumo repetido da droga. Ou seja, ao estudar o efeito de drogas como a Cannabis, não se poderia considerar a substância isolada da subjetividade do usuário. Esta posição polêmica per se reflete uma profunda reflexão fenomenológica e psicanalítica de respeito e de consideração do ser humano em sofrimento na sua mais pura radicalidade em defesa dos direitos humanos.

Richard Emil Bucher, assim, além de acadêmico, foi, sem sombra de dúvidas nenhuma, um defensor incansável da consideração e do respeito ao ser humano enquanto tal, assuma ele que condição for. Neste sentido, trabalhou em todas as frentes possíveis que um professor com formação humanista poderia tê-lo feito: no ensino, na formação de profissionais, no atendimento clínico, na produção de conhecimentos e, como conseqüência de um sério engajamento social, na proposição de atividades efetivamente sociais e comunitárias.

12 Texto do próprio professor quando da proposição do "Projeto Consultório de Rua". Vale ressaltar, aqui, finalmente, que tal projeto existe ainda hoje, consideradas as (re)adaptações feitas, sob a denominação de Natex (Núcleo de Estudos e Atenção à Exclusão Social) como uma organização não-governamental.
Por todo o exposto, reverenciando finalmente a existência ímpar deste professor junto ao Departamento de Psicologia Clínica e ao Instituto de Psicologia, portanto, junto à Universidade de Brasília, é que sustento a concessão do título de Professor Emérito da UnB ao Professor Richard Emil Bucher, post-mortem.

\section{Publicações}

\section{Artigos Científicos Publicados}

1) Bucher, R. (1971). L'angoisse dans le Test de Szondi. Revue de Psychologie et des Sciences de l'Èducation (Louvain), 6(4), 510-527.

2) Bucher, R. (1972). L'influence du romantisme allemand sur la pensée de Sigmund Freud. Les Feuillets Psychiatriques de Liège (Bélgica), 5(1), 63-76.

3) Bucher, R. (1973.) L'inquiétante étrangeté dans la Psychanalyse. Les Feuillets Psychiatriques de Liège (Bélgica), 6(4), 489-495.

4) Bucher, R. (1974). Zur Depression im Szonditest. Szondiana IX. (Schweizerische Zeitschrift für Psychologie, Beiheft), 18-34.

5) Bucher, R. (1975). La classification des ètats dèpressifs et le test de Szondi. Annales Médico-Psychologiques (Paris), 133(3), 317-345.

6) Bucher, R. (1975). La différenciation Dépression-Mélancolie à la lumière des recherches transculturelles. Psychopathologie Africaine (Dakar/Paris) 11(2), 217-237.

7) Bucher, R. (1977). Considerações sobre a atualidade do Teste de Szondi. Arquivos Brasileiros de Psicologia Aplicada, 29(3), 121-135.

8) Bucher, R. (1977). A classificação dos estados depressivos e o teste de Szondi. Arquivos Brasileiros de Psicologia Aplicada, 29(4), 73-101.

9) Bucher, R. (1977). O “estranho familiar” da/na psicanálise. Alter - Jornal de estudos Psicodinâmicos (Brasília), 7(1), 17-24.

10) Bucher, R. (1978). Aspects transférentiels dans l'application du test de Szondi. Feuillets Psychiatriques de Liege (Bélgica), 11(4), 387-411.

11) Bucher, R. (1978). "Attachment Psychology, Contato e Teoria Psicanalítica”. Psicologia Clínica e Psicoterapia (Belo Horizonte), 2(1), 5-16.

12) Bucher, R. \& cols. (1978) Tentativas de suicidio en una ciudad satélite de Brasília. Acta Psiquiátrica y Psicológica de América Latina (Buenos Aires), 24(3), 219-232.

13) Bucher, R. (1978). Os conflitos conjugais e a dialética da lei. Alter-Jornal de Estudos Psicodinâmicos (Brasília), 8(3), 21-30.

14) Bucher, R. \& cols. (1979). A influência do sexo e da atitude do aplicador em técnicas projetivas. Psicologia Clínica e Psicoterapia (Belo Horizonte), 3(1), 13-18.

15) Bucher, R. \& cols. (1979). A personalidade do alcoólatra: variáveis sócio-culturais, psicopatológicas e psicodinâmicas. Arquivos de Neuro-Psiquiatria (São Paulo), 37(3), 255-266. 16) Bucher, R. (1979). O casal neurótico perante a lei. Arquivos do Ministério da Justiça, 36(152), 264-274.

17) Bucher, R. (1979). Dinâmica conjugal e neurose. Psicologia Clínica e Psicoterapia, 3(2), 5-12. 
18) Bucher, R. \& cols. (1979). Aspectos psicopatológicos y psicodinámicos en delincuencia juvenil. Acta psiquiátrica y psicológica de América Latina, 25(3), 194-203.

19) Bucher, R. (1980). Aspectos psicopatológicos e psicodinâmicos em delinqüência juvenil. Arquivos Brasileiros de Psicologia, 32(4), 63-75.

20) Bucher, R. \& cols. (1980). A evolução psicopulsional de crianças brasileiras. Arquivos Brasileiros de Psicologia (Fundação Getúlio Vargas), 32(3), 73-97.

21) Bucher, R. \& cols. (1980). Ordem de nascimento e relacionamento fraterno de pacientes esquizofrênicos. Arquivos de NeuroPsiquiatria, Jornal da Academia Brasileira de Neurologia (São Paulo), 38(1), 53-64.

22) Bucher, R. (1980). Attachement et Pulsion. Les Feuillets Psychiatriques de Liège, 13(3), 328-350.

23) Bucher, R. (1980). O impacto transferencial em técnicas projetivas. Estudo com o teste de Szondi. Psicologia clínica e Psicoterapia (Belo Horizonte), 4(1), 25-37.

24) Bucher, R. (1980). Loucura e Linguagem em Hölderlin [Psicose, Poesia e Linguagem - Reflexões sobre vida, obra e loucura de Hölderlin]. Estudos de Psicanálise Círculo Brasileiro de Psicanálise (Belo Horizonte), 9, 71-84.

25) Bucher, R. \& cols. (1980). Aspectos psicopatológicos e psicodinâmicos na delinquência juvenil. Arquivos Brasileiros de Psicologia, 32(4), 63-75.

26) Bucher, R. (1981). Psicologia Científica: Realidade ou Mito? Psicologia: Ciência e Profissão (CFP-Brasília), 1(1), 11-37.

27) Bucher, R. (1981). Do "Trieb" de Freud e das vicissitudes de sua tradução. Em M. M. Freitas (Org.), Psicanálise: Feminino, Singular (pp. 55-78). São Paulo: Ed. Loyola.

28) Bucher, R. \& cols. (1981). Aspectos psicológicos e psicodinâmicos do diabético. Acta psiquiátrica y psicológica de América Latina, 27(2), 117-123.

29) Bucher, R. (1981). Freud hoje. Em R. Bucher (Org.), A presença de Freud no mundo contemporâneo (pp. 1-4). Brasília: Editora da UnB.

30) Bucher, R. (1981). Freud e as vicissitudes da sexualidade humana. Em R. Bucher (Org.), A presença de Freud no mundo contemporâneo (pp. 75-89). Brasília: Editora da UnB.

31) Bucher, R. \& cols. (1981). Tentativas de suicídio segundo o sexo e idade. Acta Psiquiátrica y Psicológica de América Latina (Buenos Aires), 27(1), 39-43.

32) Bucher, R. (1981). Psiquiatrização e valores humanos. Revista Brasiliense de Psiquiatria, 4, 89-95.

33) Bucher, R. (1981). As pretensões da psicologia científica: Realidade ou Mito? Análise Psicológica (Lisboa), 1(2), 101-114.

34) Bucher, R. \& cols. (1982). A Psico-Oncologia e sua contribuição à abordagem multifatorial do câncer. Acta Psiquiátrica y Psicológica de América Latina, 28(2), 129-142.

35) Bucher, R. \& cols. (1982). Ciência e Imaginação. Ciência e Cultura, 34(4), 497-501.

36) Bucher, R. \& Romankiewicz, E. (1982). A estrutura psicopulsional de um grupo indígena brasileiro. Arquivos Brasileiros de Psicologia, 34(4), 95-112.

37) Bucher, R. (1982). Ansiedade e Sociedade: uma visão psicológica. Diálogo Médico (Roche), 9(1), 30-32.

38) Bucher, R. (1982). O valor estrutural do "Complexo de Édipo". Alter - Jornal de Estudos Psicodinâmicos (Brasília), 12(1), 25-44.
39) Bucher, R. (1982). Marginalização Social e Dificuldades de Integração da Personalidade. Alter - Jornal de Estudos Psicodinâmicos (Brasília), 12(2), 85-96.

40) Bucher, R. (1982). Ideologia e Psicanálise. Trabalhos apresentados em: Mini-Encontro Nacional do Centro de Estudos Freudianos (pp.11-21). Porto Alegre, 10 e 11 de setembro de 1982.

41) Bucher, R. (1983). Fenomenologia e Psicanálise. Revista Brasiliense de Psiquiatria, 3(1), 33-44.

42) Bucher, R. \& cols. (1984). O sujeito: Limite epistemológico da psicanálise. Arquivos Brasileiros de Psicologia, 36(4), 76-89.

43) Bucher, R. (1984). O Umbigo de Freud. Em J. Birman \& C. A. Niceas (Orgs.), O Objeto na Teoria e na Prática Psicanalítica (pp. 142-163). Rio de Janeiro: Editora Campus.

44) Bucher, R. \& cols. (1984). A Estrutura de Personalidade do Toxicômano. Acta Psiquiátrica y Psicologica de America Latina, 30(3), 209-219.

45) Bucher, R. (1984). Transferência e Polêmica em Psicanálise. Alter - Jornal de Estudos Psicodinâmicos, 14(3), 133-139.

46) Bucher, R. (1985). "As Histórias que ninguém conta”. O mito familiar na vida do neurótico. Psicologia: Teoria e Pesquisa, 1(1), 7-18.

47) Bucher, R. \& cols. (1985). A Abordagem Terapêutica do Toxicômano. Acta Psiquiátrica y Psicológica de América Latina, 31(2), 113-130.

48) Bucher, R. \& cols. (1985). Modelos de atendimento a toxicômanos. Arquivos Brasileiros de Psicologia, 37(3), 70-83.

49) Bucher, R. \& cols. (1986). Influências e estruturas psicológicas no câncer da mama. Acta Psiquiatrica y Psicologica de America Latina, 32(3), 70-83.

50) Bucher, R. (1986). Influências e Estruturas Psicológicas no Cancer da Mama. Acta Psiquiatrica y Psicologia de America Latina, 32(4), 271-280.

51) Bucher, R. (1986). O Consumo de Drogas: evoluções e respostas recentes. Psicologia: Teoria e Pesquisa, 2(2), 132-144.

52) Bucher, R. (1986). A Toxicomania, paradigma da dependência humana. Humanidades (UnB), 10, 60-68.

53) Bucher, R. (1986). Questões cruciais do atendimento a toxicômanos. Análise Psicológica (Instituto Superior de Psicologia Aplicada), 2, 197-214.

54) Bucher, R. (1986). Farmacodependência e Psicofarmacologia. Acta Psiquiátrica y Psicológica de América Latina, 32, 9-10.

55) Bucher, R. (1987). O Jovem e a Transgressão. Humanidades $(U n B), 14,16-21$.

56) Bucher, R. \& cols. (1988). Conhecimentos e uso de drogas entre alunos de Brasília. Psicologia: Teoria e Pesquisa, 4(1), 12-21.

57) Bucher, R. (1988). Conocimiento y uso de drogas entre alumnos de Brasília. Acta psiquiatrica e psicologica de America Latina, 34(2), 113-126.

58) Bucher, R. (1988). O preço da cultura segundo Freud. Humanidades (UnB), 16, 44-49.

59) Bucher, R. \& cols. (1988). Influência de sexo e idade em consumidores de drogas em Brasília. Psicologia: Teoria e Pesquisa, 4(1), 12-21.

60) Bucher, R. (1988). Psicopatologia da toxicomania e vivência do toxicômano. Revista Brasileira de Saúde Mental (DINSAM/MS), 2(2-3), 34-42.

61) Bucher, R. (1988). La toxicomanie, paradigme de la dépendance humaine. Psychotropes (Montréal-Bruxelles), 4(3), 19-26. 
62) Bucher, R. \& cols. (1989). À Procura de uma Abordagem Interdisciplinar da Toxicomania. Arquivos Brasileiros de Psicologia (Fundação Getúlio Vargas), 41(1), 111-127.

63) Bucher, R. (1989). É a psicanálise uma ciência? Humanidades (UnB), 20, 68-71.

64) Bucher, R. (1989). Consumo de drogas e direitos humanos. Humanidades (UnB), 22, 80-87.

65) Bucher, R. (Org.) (1989). Drogas: Como compreender? O que fazer? (Cartilha). Brasília: Fundação O.K.

66) Bucher, R. (1989). O CORDATO: Concepção Geral e Funcionamento. Em: Encontros de centros brasileiros de tratamento de dependências de drogas (pp. 99-114). São Paulo: AFIB-EPM.

67) Bucher, R. (1990). Psicoterapia versus Psicanálise? Arquivos Brasileiros de Psicologia, 42(1), 3-21.

68) Bucher, R. \& cols. (1990). Drogas utilizadas por jovens de Brasília. Psicologia: Teoria e Pesquisa, 6(1), 75-85.

69) Bucher, R. (1991). Consumo de inalantes e condições de vida de menores da periferia de Brasília. Revista da ABP/APAL, 13(1), 18-26.

70) Bucher, R. (1991). Psicanálise e direitos humanos. Humanidades (UnB), 7(3), 233-239.

71) Bucher, R. \& cols. (1991). Normas e procedimentos na abordagem do abuso de drogas. Brasília: Ministério da SaúdeCORSAM.

72) Bucher, R. (1991). L'Éthique des interventions et les droits de l'homme. Em Actes du Colloque Scientifique International "Toxicomanie et condition humanine" (pp. 147-159). Paris: Sorbone/Centre Médical Marmottan.

73) Bucher, R. (1991). Da Formação do Psicanalista, ou da Lógica do Impossível. Revista d' isso - Centro de Estudos Freudianos de Brasília, 2(1).

74) Bucher, R. (1992). A ética da prevenção. Psicologia: Teoria e Pesquisa, 8(3), 385-398.

75) Bucher, R. (1992). Freud na virada do Século. Humanidades (UnB), 29, 303-307.

76) Bucher, R. (1993). Desafios para a Educação Preventiva. Em: Centro Mineiro de Toxicomania: 10 anos. Ata da VI Jornada (pp. 59-62). Belo Horizonte: FHEMIG.

77) Bucher, R. (1993). As Drogas e as Ideologias de Prevenção. Em C. L. INEM, \& G. Acselrad, (Orgs.), Drogas: Uma visão contemporânea (pp. 31-42). Rio de Janeiro: Imago Editora.

78) Bucher, R. (1993). A psicanálise: desafio para a psicologia? Em R. Bucher, R. \& S. F. C. Almeida (Orgs.), Psicologia e Psicanálise: Desafios (pp. 9-18). Brasília: Editora da Universidade de Brasília.

79) Bucher, R. (1993). O Trieb entre Mito e Destino. Revista d' isso - Centro de Estudos Freudianos de Brasília, 2(2).

80) Bucher, R. \& cols. (1994). O discurso do "combate às drogas" e suas ideologias. Revista de Saúde Pública, 28(2), 137-145.

81) Bucher, R. \& cols. (1994). Acerca de delinqüência juvenil e consumo de drogas. Psicologia: Teoria e Pesquisa, 10(2), 287-297.

82) Bucher, R. (1995). Viewpoint: Quality of Life and Drug Use - Drug Use in Modern Societies: Perspectives, trends, and meanings Drugs: Education, prevention and policy, 2(2).
83) Bucher, R. (1995). A Avaliação Qualitativa dos Atendimentos a Usuários de Drogas. Revista ABP-APAL, 17(2), 75-86.

84) Bucher, R. (1995). Drogas na Sociedade. Em Drogas, Aids e Sociedade - Programa Nacional de Doenças Sexualmente Transmissíveis/AIDS - PN DST/AIDS (pp. 33-52). Ministério da Saúde.

\section{Artigos/Ensaios/Reportagens/Textos/Rascunhos - possivelmente não publicados}

N1) Bettelheim, Bruno: Freud e a Alma Humana (1986)

N2) A Ansiedade na Vida Social.

N3) A Ética da Psicanálise

N4) A Fala do Homem e o seu Agir

N5) A Formação do Psicólogo Clínico. Contribuição à Mesa Redonda "A formação profissional da área da Saúde Mental", da II Jornada de Psiquiatria do DF (1983)

N6) Caminhos de Políticas de Drogas: A Suíça e o Brasil (1987)

N7) Considerações sobre "Drogas e Transito" (1987)

N8) Desejo de Psicanálise....? Richard Bucher/ Arlete Machado Mourão

N9) Dificuldades e Possibilidades do Atendimento ao Usuário de Drogas no Brasil

N10) Dimensões Sociais da Toxicomania Moderna

N11) Freud (re)sumido

N12) Freud na Ciência e no Mercado

N13) Modelos para a Evolução do Consumidor de Drogas (A Carreira do Drogado)

N14) O Confem e as Drogas

N15) O Consumo de Entorpecentes: A sua Evolução, Compreensão e Repressão

N16) O Lugar da Depressão

N17) Os Dilemas do Ensino de Psicanálise. Folhetim - Folha de São Paulo - 29/11/1981

N18) Pirraça, Pirueta e Pipoco (1988)

N19) Prevenção no Brasil: Concepção Geral e Instituições (Relatório) (1991)

N20) Reflexões acerca da "personalidade do toxicômano"

N21) Teorias Psicanalíticas II

N22) XV Encontro Nacional 12 a 15/06/1984

N23) A Função da Droga no (Dis)funcionamento Social

N24) A Abordagem Psicodinâmica da Entrevista Clínica e do Laudo Psicológico. Richard E. Bucher e Priscila F. Costa

N25) A Formação de Multiplicadores na Prevenção da SIDA/AIDS entre Usuários de Drogas, no Brasil. (CORDATO)

N26) Experiências de Prevenção no Trabalho com AIDS e Drogas (Mesa Redonda). Seminário Estadual sobre Aids e Drogas (UERJ) (1994)

N27) Editorial: Fim da Psicanálise no ano 2000?

N28) A Função Social da Droga e a Questão da Descriminalização. (Texto p/ publicação do CONFEN/ SNE, após palestra no TSJ, em $12 / 12 / 1994)$

N29) Narcisismo e Self

N30) O Pai do Nome-do-Pai (Sybille Lacan: Um pai. Rio de Janeiro: Editora Bertrand Brasil (1996) 
N31) Dos Campos Pampas a Mil Brotões (Impressões Marginais do III Encontro Internacional do Campo Freudiano em Buenos Aires - Julho de 1984)

N32) As Drogas e a Opinião Pública. Jornal Estado de São Paulo, 04/03/96, pg. C8

N33) Um Estudo Comparativo com o Teste de Szondi com uma População Indígena Brasileira

N34) O Usuário de Drogas Injetáveis na Política Preventiva ao HIV/AIDS (UDI's na política preventiva ao HIV/AIDS)

N35) As Drogas na Sociedade Brasileira [Curso a distância, Cap. 11 (3a versão - rascunho)]

N36) Qualidade de Vida e Consumo de Droga

N37) A Situação da Prevenção ao Uso Indevido de Drogas no Brasil (2o documento de trabalho para a reunião técnica do MEC sobre educação preventiva, março de 1992, elaborado por Richard Bucher)

\section{Artigos/Ensaios/Reportagens/Textos/Rascunhos em outras línguas - possivelmente não publicados}

N38) Chemins de Politiques de Drogues: La Suisse et le Brésil

N39) Compte - Rendu pour CIOMPI, L. et MUELLER, C.: Lebensweg und Klter der Schizophrenen (em francês)

N40) Das Unheimliche (in) der Psychoanalyse

N41) Compte - Rendu pour PSYCHOPATHOLOGIE AFRICAINE de: AVENARIUS, R.: Der Grössenwahn (em francês)

N42) Résumé de la dissertation doctorale: Dépression et Mélancolie

N43) L' Usage de Solvents par les Enfants de Rue du Bresil: Propositions de Prevention

N44) Structures Pulsionnelles Depressives et Melancoliques

N45) ?El Psicoanalisis Termina en el 2000?

\section{Livros e Teses}

1) Bucher, R. (1977). Depression und Melancholie. Eine historische und triebpsychologische Untersuchung zur Klassifierung und Strutur der Depressionszustände. Tese de Doutorado, Bern: Verlag Hans Huber.

2) Bucher, R. (1979). Depressão e Melancolia. Estrutura e classificação dos estados depressivos. Rio de Janeiro: Zahar editora.

3) Bucher, R. (Org.) (1988). As Drogas e a Vida. Uma abordagem bio-psico-social. São Paulo: EPU.

4) Bucher, R. (1989). A Psicoterapia pela Fala. Fundamentos, princípios, questões. São Paulo: EPU.

5) Bucher, R. (Org.) (1989). Prevenção ao Uso Indevido de Drogas, Volume 1. Curso à distância, CEAD/Editora da UnB.

5) Bucher, R. (Org.) (1989). Prevenção ao Uso Indevido de Drogas, Volume 2. Curso à distância, CEAD/Editora da UnB.

6) Bucher, R. (Org.) (1989). Em Cartilha: Valores Humanos, Corpo e Prevenção. A procura de novos paradigmas para a educação física. Brasília: SEFD/MEC.

7) Bucher, R. (1992). Drogas e drogadição no Brasil. Porto Alegre; Artes Médicas Editora.

8) Bucher, R. (1992). Drogas: O que é preciso saber para prevenir. São Paulo: Fundo Social de Solidariedade - Governo do Estado de São Paulo- CONEN/SP.

9) Bucher, R. (1996). Drogas e Sociedade nos Tempos da AIDS - UnB - Brasília.

10) Zum Begriff des "Zusammenhangs" im Werke Sigmund Freuds. Universite de Louvain/ Belgique, 1969.

11) Karl Korsch, Vertreter eines Authentischen Marxismus. Universite Catholique de Louvain, 1968. 